have been stable since at least 1974 . This pattern is about to be altered quite abruptly by AIDS.

Our predictions make several assumptions. They will be overestimates if the current educational programme dramatically changes sexual habits or if an effective vaccine or treatment is found. They will be underestimates if the disease continues to spread unchecked through the large uninfected pool of heterosexuals, if there has been much underreporting, or if the incubation period is longer than 52 months. ${ }^{6}$ Given the evidence for the heterosexual spread of AIDS and the years taken to discover a vaccine for other viral conditions, we believe these predictions to be reasonably conservative.

Two issues arise from the picture shown by our figures. The current preponderance of ischaemic heart disease, lung cancer, and chronic obstructive airways disease stands out clearly. All of these conditions have a major smoking component, yet this preventable cause has been the subject of masterly inactivity for many years. Secondly, because AIDS will rank with the top causes of premature death within the next few years there is a massive need for preventive resources now. This need is being heeded to some extent by national advertising and the specific allocation of $£ 20 \mathrm{~m}$. But such specific allocations tend to lead to the assumption that AIDS needs only these marginal resources. The pattern of premature death described here could well be used to change that thinking and encourage the local transfer of mainstream resources, ever frozen into traditional patterns of use.

A J H STEVENS E S SEARLE G P A WINYARD

Department of Service Development and

Community Medicine,

Lewisham and North Southwark

Health Authority,

London SE1 9RY

1 McEvoy M, Tillett HE. Some problems in the prediction of future numbers of cases of the acquired immunodeficiency future numbers of cases of the acquired

2 Tillett HE, McEvoy $M$. Reassessment of predicted numbers of AIDS cases in the UK. Lancet 1986;ii:1104.

3 Mortimer PP. Estimating AIDS, UK. Lancet 1985; i: 1605.

4 Brookmeyer R, Gail MH. Minimum size of the acquired immunodeficiency syndrome (AIDS) epidemic in the United States. Lancet 1986;ii:1320-2.

5 Richards T. The pathology of AIDS. BrMed f 1985;291:1630-1. 6 Lui KJ, Lawrence DN, Morgan WM, et al. A model based approach for estimating the mean incubation period of transfusion-associated acquired immunodeficiency syndrome. Proc Natl Acad Sci USA 1986;83:3051-5.

\section{HIV antibody testing}

SIR,-In their report of Henoch-Schönlein purpura associated with legionnaires' disease (24 January, p 220) Dr P W Bull and colleagues say that in view of the patient's social history skin biopsy was postponed pending the result of a test to determine whether he was positive or negative for antibody to human immunodeficiency virus (HIV). By the time they knew that the test had yielded negative results the skin eruption had faded, so a specimen could not be obtained for histological examination.

There are two important points to make about this report. Firstly, a negative test result for antibody to HIV should not be regarded as evidence of freedom from infection with that virus in a patient with a relevant social history; three months or more may elapse after infection before the test result becomes positive. Secondly, a patient should not be deprived of any necessary investigation pending the result of an HIV antibody test. In this particular case lack of a skin biopsy did not affect the patient's treatment and eventual recovery. In other circumstances, how- ever, lack of one or more diagnostic tests could seriously impair diagnosis and treatment.

HIV is likely to spread. All doctors, nurses, and laboratory staff must therefore learn to look after patients and to handle their specimens safely without detriment to the care of patients. Experience in the United States and elsewhere in the past five years has shown that the risk to health workers of acquiring HIV from patients is exceedingly small. The recent publication by the health services advisory committee of the Health and Safety Commission on the labelling, transport, and reception of specimens, which should be read by all concerned, emphasises that there is a need to ensure that all specimens are safely contained and transported from the patient to the laboratory.

\section{CE D TAYLOR}

\begin{abstract}
Clinical Microbiology and
Public Health Laboratory,

Addenbrooke's Hospital,

Cambridge CB2 2QW
\end{abstract}

\section{Dally, O'Donnell, and the GMC}

SIR,-I have no doubt that $\mathrm{Dr}$ Michael O'Donnell's article (14 February, p 451) will cause some anxiety. As I was not sitting on the professional conduct committee on the occasion to which he refers I cannot comment on the events he describes, which would, in any case, be improper, but I would like to comment on the principles.

Though it may not be clear to anyone reading the article, the professional conduct committee goes to considerable lengths to prevent any confidential matter used during its hearings being related to an identifiable individual unless a witness assures the committee that he or she has no objection. In some instances this can be achieved effectively by the committee allowing the witness to write down his name and address and thereafter referring to him by an initial. Alternatively, if the identity of the witness cannot be concealed in this way, the committee willingly goes into private session to hear sensitive evidence. There is no question of the committee treating confidential matters casually.

A more difficult problem arises, however, when evidence to be put before the committee derives from case records or other confidential sources. It is essential, for obvious reasons, that the respondent doctor must be able and willing to identify to those at the hearing the person to whom the records refer, and clearly, in the absence of the patient's consent, this constitutes a breach of confidentiality. In no such case will the public be aware of the patient's identity. It is the normal practice of the committee to insist that consent for disclosure should be sought from the patien concerned, but there are circumstances in which this may be impossible.

If the matter before the committee concerns the alleged improper prescribing of controlled drugs hundreds of patients may be affected, which makes it impracticable to contact every one, even if they can be found and are willing to consent to disclosure, which is less than certain in a case of this kind. It is, of course, quite untenable to suggest, as Dr O'Donnell does, that problems of confidentiality could be averted by changes in the drafting of charges. How could a matter relating to improper prescribing be considered without reference to the condition for which prescription was alleged to be necessary? Similarly, difficulties over consent may arise when a doctor is subject to a complaint from one of his patients, who will almost certainly refuse to allow the disclosure of medical information that would call into question the validity of his evidence against the doctor. In circumstances such as these the committee is faced with the choice of failing in its duty to ensure that justice is done or accepting evidence of a confidential nature without the appropriate consent

The blue book is not a statutory document but advice to the profession on how to conduct itself, which indicates that certain actions or omissions may render the doctor liable to a charge of having committed serious professional misconduct. At no point does it suggest that such a judgment is automatic, and a valid defence, such as serving the interest of the patient, may be acceptable. The same applies to the work of the professional conduct committee. It rarely admits evidence that would breach professional confidence, but it must retain the right to do so should the interests of ustice demand it. In all circumstances such information will remain with the committee and its immediate associates, whose procedures are designed to prevent it from becoming public property.

DAVID BoLT Chairman,

Honiton, Professional Conduct Committe

Devon EX14 0BE

SIR,-May I suggest that in honour of Ms Wendy Savage a new verb be introduced into medical terminology: "to be savaged." In my view Dr Ann Dally has just been savaged by the General Medical Council (GMC).

It has been an open secret that the Home Office has been concerned about Dr Dally for some time as she is a private practitioner in drug dependence and she still prescribes injectable methadone. This is still an acceptable treatment but has recently been held to be less orthodox. (I would draw attention to the Guidelines of Good Clinical Practice in the Treatment of Drug Dependence. These guidelines are now apparently recognised, by the GMC at least, as a code of practice. In my opinion these guidelines are a useful first draft but would need much more work and much wider consultation before they would be suitable for anything approaching a code of practice, even supposing that we should have such codes in clinical practice.)

Until five years ago the state did not see that drug use was rapidly growing. Then, when the government did so, in a moral panic it embarked on a war against drugs. Sadly, the first victims of war are truth and justice. The government quite forgot and has still forgotten the need for adequate treatment facilities, including access to a clean, legal, and well regulated supply of drugs. Dr Dally continued to prescribe such drugs and met a very real need, which was not being served by the NHS.

The tribunals set up under the Misuse of Drugs Act, which could have prevented Dr Dally from prescribing controlled drugs, would not have been able to find her practice unacceptable. The GMC has taken a different view and for the second time found against Dr Dally.

I gave evidence for Dr Dally and was present to hear the end of her own evidence. I was asked about the ethics of treating privately patients dependent on drugs who did not seem to be able to afford such care. I had already been in correspondence with the GMC on this issue before I had any idea that I was to give evidence for Dr Dally. The chairman did not seem to appreciate the subtlety of my argument and asked me not to continue as there were reporters present and he did not wish my views to be attributed to a doctor or to the tribunal. I was and am still puzzled by his argument.

It struck me that the GMC is prosecutor, judge, jury, and executioner. The medical profession is as a whole hostile to drug dependent patients, and, as will happen with such an attitude, the carers are stigmatised as well. In cases where the care of drug dependent patients is at issue the GMC reflects this 